\title{
Blockchain Applications in Agribusiness: A Systematic Review
}

\author{
Geneci da Silva Ribeiro Rocha ${ }^{1}\left(\mathbb{D}\right.$, Letícia de Oliveira ${ }^{2, *(\mathbb{D})}$ and Edson Talamini ${ }^{2}$ (D) \\ 1 Interdisciplinary Center for Studies and Research in Agribusiness-CEPAN, Universidade Federal do Rio \\ Grande do Sul-UFRGS, Rio Grande do Sul 90040-060, Brazil; geneci.6813.srr@gmail.com \\ 2 Department of Economics and International Relations-DERI, Faculty of Economics, and Interdisciplinary \\ Center for Studies and Research in Agribusiness-CEPAN, Universidade Federal do Rio Grande do \\ Sul_UFRGS, Rio Grande do Sul 90040-060, Brazil; edson.talamini@ufrgs.br \\ * Correspondence: leticiaoliveira@ufrgs.br
}

Citation: Rocha, G.d.S.R.; de Oliveira, L.; Talamini, E. Blockchain Applications in Agribusiness: A Systematic Review. Future Internet 2021, 13, 95. https://doi.org/ 10.3390/fi13040095

Academic Editor: Ahad ZareRavasan

Received: 19 February 2021

Accepted: 5 April 2021

Published: 8 April 2021

Publisher's Note: MDPI stays neutral with regard to jurisdictional claims in published maps and institutional affiliations.

Copyright: (c) 2021 by the authors. Licensee MDPI, Basel, Switzerland. This article is an open access article distributed under the terms and conditions of the Creative Commons Attribution (CC BY) license (https:// creativecommons.org/licenses/by/ $4.0 /)$.

\begin{abstract}
Blockchain is a technology that can be applied in different sectors to solve various problems. As a complex system, agribusiness presents many possibilities to take advantage of blockchain technology. The main goal of this paper is to identify the purposes for which blockchain has been applied in the agribusiness sector, for which a PRISMA-based systematic review was carried out. The scientific literature corpus was accessed and selected from Elsevier's Scopus and ISI of Knowledge's Web of Science (WoS) platforms, using the PRISMA protocol procedures. Seventy-one articles were selected for analysis. Blockchain application in agribusiness is a novel topic, with the first publication dating from 2016. The technological development prevails more than blockchain applications since it has been addressed mainly in the Computer Sciences and Engineering. Blockchain applications for agribusiness management of financial, energy, logistical, environmental, agricultural, livestock, and industrial purposes have been reported in the literature. The findings suggest that blockchain brings many benefits when used in agribusiness supply chains. We concluded that the research on blockchain applications in agribusiness is only at an early stage, as many prototypes are being developed and tested in the laboratory. In the near future, blockchain will be increasingly applied across all economic sectors, including agribusiness, promoting greater reliability and agility in information with a reduced cost. Several gaps for future studies were observed, with significant value for science, industry, and society.
\end{abstract}

Keywords: Internet of Things; information technology; innovation; supply chains; transparency; traceability; safety; food systems; transactions; smart contracts

\section{Introduction}

Agribusiness is a sector of paramount importance for a country; its potential is the result of a set of several factors, especially investments in technology and research, which can increase productivity. The agribusiness aggregate is composed of several inputs or product supply chains operating in different natural ecosystems. In a supportive context, the supply chains are embedded in an institutional environment formed by financial, $R \& D$, and technical assistance organizations and institutions with a strong influence on their performance [1].

Supply chains involve a set of activities that are gradually structured from the production to manufacturing and marketing of a product or service. A supply chain is understood to be the operations involving everything from the manufacturing of inputs, production on the farm, transformation process (industrialization), distribution, and trading to reach the end consumer [2]. Thus, the agribusiness supply chains of a country may have great prominence all over the world since they are complex, diversified, and dependent on the organization of each link in the productive system and the relation between them. The farmers operate in a strong, participative, and comprehensive system with an increasingly interconnected integration within a wide business and cooperation network. A farm represents an important node, integrated with other nodes such as infrastructure, commerce, 
finance, technology, labor relations, and the entire public and private institutional apparatus $[2,3]$. In addition to the number of actors and transactions, their complexity is increasing over time, taking into account the countless amount of country-specific economic, political, environmental, social, cultural, legal, and sanitary norms and conventions [3].

Many resources are changed through the links between actors involved in an agribusiness supply chain. In one direction, there is a flow of products and services, while in the opposite direction, financial resources are exchanged. Today, information is a valuable resource, which flows both forward and backward [4,5]. Information sharing is subject to many benefits and constraints depending on objectives, interests, technology, trust, and control, among other factors [6]. The asymmetric nature of information and misinformation is a constant challenge to be overcome in supply chain management, and consumers are demanding traceable products, transparency, and safety information [7-10].

The fast growth and development of information technology, attributed to a platform of public services aiming to improve the management of distant resources and services, became the key to solving frictions between the demand and supply of products in organizations [10]. The blockchain is a communication network where data are stored and shared in a distributed manner between all links, eliminating any trusted authority centralized in different business models, and where each node can coordinate without a unified data center [11]. The concept was introduced in 2009 by the pseudonymous Satoshi Nakamoto, who created Bitcoin to solve double-spending problems. The nodes in the Bitcoin network incorporate mutually agreed validations on the blockchain, carrying the transactions on the ledger, that is, a kind of cash book determining who has data in that chain [12].

Blockchain is considered a technological innovation that comes from the incorporation of existing technologies and, lately, has received more attention due to its autonomy, anonymity, and data immutability, becoming an emerging subject in science and organizations [11]. It is a distributed database, in which a group of people controls, registers, and shares information, that can be used in different kinds of applications and is interconnected through platforms and hardware all over the world. It has been identified as a technology that has a concept based on a protocol that is inviolable to human action and it is also based on three underlying technologies: peer-to-peer networks (P2P), cryptography, and distributed consistency algorithms [13]. It is also accompanied by a smart contract, which is not a necessary part of blockchain-based systems but provides natural support for transactions carried out using the technology [14].

A blockchain is a chain of information blocks interconnected in the digital environment of the internet, allowing for information on transactions of various kinds to be stored, linked, and recovered, forming a large database [15]. The blockchain networks can be categorized into public, private, and federated blockchains, based on the network management system adopted and the permissions allowed [16]. A private blockchain is a permissioned access platform; a public blockchain is a permissionless open data network in which any user can add data in the form of a transaction, which is an identification data package in the system, and these data can also be checked and copied; a federated blockchain combines the features of both private and public blockchains $[16,17]$.

Blockchain technology is claimed to be a technology of inviolable validation, having decentralization as a safety measure that creates consensus and confidence in direct communication between two parts, without third party intermediation. It is appropriate for situations requiring privacy, identity control, and permissions $[17,18]$. Thus, a blockchain provides immutability, transparency, and almost instantaneous insurance in the form of information shared between two or more participants in a single transaction, eliminating the need for third parties, creating an immutable record which can be seen by all the relevant parties without being altered.

When addressing the blockchain theme, it is common to think of cryptocurrencies, especially Bitcoin. However, experts in technology and economics are signaling that blockchains may be relevant in technological research and can be used in many areas in addition to Bitcoin [19]. Many organizations have integrated technologies which have been 
changing the environment and markets, making it easier to develop activities favoring all parts of the process, including the agribusiness segments, resulting in positive contributions to the agri-food supply chain.

The current agribusiness supply chains are ineffective because their integrity can be easily counterfeited. Blockchain applications have the potential for automated control in which the product is traced from the farm to the consumer's table, depending on the 3P's (party, product, and premises) conditions; with this technology, the end consumer can select the product they want to consume, with safety in the product quality. In addition to the product quality differential, the price received by the producer tends to be higher because of the guarantees. In this way, blockchains can improve traceability in agribusiness, adding value not only for the producer but the entire production chain as well. Thus, an infrastructure supported by the use of this technology can help guarantee food safety, as effective tracking reduces losses in the logistic process [7-10,19-23]. Blockchain applications have been reported for other purposes related to agribusiness, such as precision agriculture and environmental monitoring [24], transactions certification [25], smart agriculture and smart contracts [26], consumer-retailer relationships [27,28], sustainability and coordination, performance, and order management [29], development of safer algorithms [30], and fair-trading practices [31].

Although blockchain is a new technology, its uses and potential applications in agribusiness are already being reported. However, the literature lacks studies that investigate the purposes for which blockchain technology has been employed. Therefore, this study is conducted using the following research question: what are the purposes for which blockchain has been applied in agribusiness supply chains? The main goal is to identify the purposes for which the blockchain has been applied in the agribusiness sector.

The article is structured in five sections. The first section addresses the subject, evidencing the research problem and objective. The second section explains the methodological procedures used to achieve the objective. In the third section, the data analysis is presented and discussed; conclusions, limitations, and suggestions for future studies are offered in the last section.

\section{Materials and Methods}

In this section, the steps and techniques used to achieve the objective of this research are presented. The study is exploratory and quali-quantitative in its nature. A systematic review of the literature was accomplished to solve the research question and reach the objective. The review was based on articles indexed in the Elsevier's Scopus and ISI of Knowledge's Web of Science (WoS) databases searched on 5 July 2019, with no restriction on the date of publication. Relevant and high-impact studies were selected, taking into account the databases chosen.

Following the procedures stated by the PRISMA protocol, a bibliometric review followed by a systematic content analysis of the articles was carried out. Bibliometrics is a quantitative and statistical technique for systematically measuring production indexes that contribute to the topic in the academic environment, characterized by measuring the influence of journals, researchers, and their trends [32]. The PRISMA protocol helps researchers improve the reporting of systematic reviews or meta-analyses, since it is based on an objective question, uses detailed and clear methods, and allows for identifying, selecting, and critically evaluating the most relevant research on the studied subject [33].

The systematic review is presented in the following steps: (i) formulate the research question; (ii) define the inclusion or exclusion criteria; (iii) select and evaluate the quality of the literature included in the study; and (iv) analyze, synthesize, and disseminate the results [34]. This choice was made due to its reliability as well as the methodological rigor necessary to develop it. Likewise, its scope allows a general analysis of the articles' contents, with a clear structuring of the information found [35]. The analysis continues with two phases of operational procedures: 
First phase: two search queries were used in the databases (Scopus and WoS) to retrieve a larger number of studies. The following keywords were inserted in the search engine: the first attempt started using the terms "agr" and "blockchain", or "block chain" and "block-chain", returning 82 articles in the Scopus database and 221 in WoS, totaling 303 studies. In the second attempt, the search was carried out with the keywords "blockchain", and a sub search inserting the term "agr"; it found 266 studies in Scopus, and 160 in WoS, totaling 426 articles, as shown in Figure 1. The terms were searched under "title", "abstract", and "keywords", selecting "article" as the type of document.

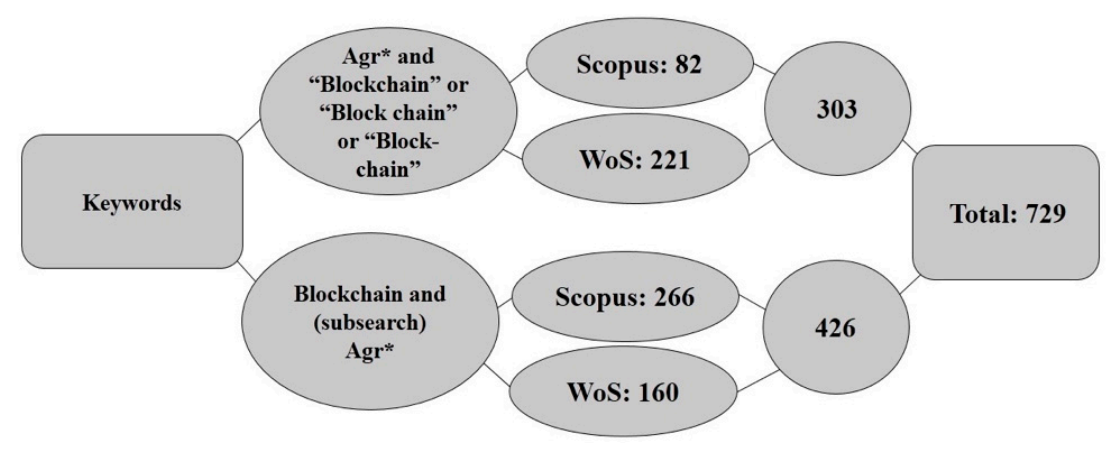

Figure 1. Search criteria and documents retrieved in Scopus and Web of Science databases.

On completing this procedure, 729 articles were found. Then, the methodology of the PRISMA protocol was applied, as shown in Figure 2.

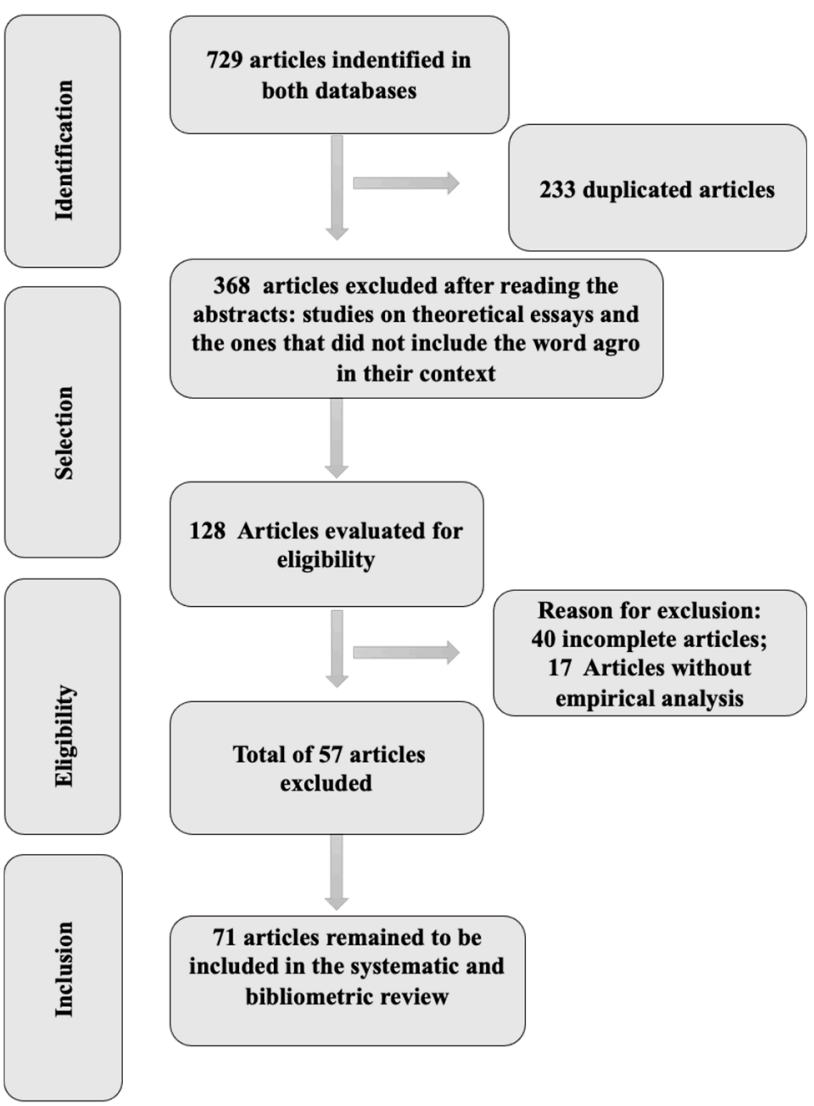

Figure 2. PRISMA flowchart and selection of articles for bibliometric and systematic review.

Figure 2 shows that, of the 729 articles found in the survey, only 71 met the four steps of the protocol: identification, selection, eligibility, and inclusion. The articles that did not have agribusiness as the study objective, those that did not make their full text available on 
the web, and those dealing with theoretical and bibliometric works, systematic reviews and literature analyses were disregarded. However, the excluded articles contributed to a better comprehension of the subject under study, since they were reviews of blockchain. Thus, during this stage, it was required that the central theme of an article for inclusion was blockchain and agribusiness, being the selected articles on the applications of blockchain for some purpose related to agribusiness.

Second phase: frequency of articles over time, areas of knowledge, number of publications per country, institutions, and authors, as well as the word cloud, were defined as the main bibliometric indicators; objectives, methodological procedures, purposes for blockchain application, and countries where the study was developed were the most important topics for the systematic review. The analysis and discussion of the results were developed through a quali-quantitative analysis, making a systematic review of the articles by reading each of them in depth and extracting fragments of interest.

\section{Results and Discussion}

In the search for results regarding the purposes for which blockchain has been applied in the agribusiness supply chains, bibliometric analyses and discussions based on a systematic review of the literature were used to find evidence from studies. Therefore, this section presents the main results from the bibliometric analyses, and a qualitative systematic review on the purposes for blockchain application.

\subsection{Bibliometric Analysis}

The bibliometric results are outlined in different parameters, such as chronological evolution, areas of publication, countries, institutions, and authors that have published on the subject. We found that an article from 2016 was the earliest publication in WoS, when no publication about blockchain in agribusiness was retrieved in the Scopus database. In 2017, two studies in Scopus and five in WoS were identified; in 2018, Scopus presented eight publications and WoS, 13. In 2019, there was a substantial increase to 32 documents in Scopus, and 10 in WoS, showing that the subject is a recent hot topic.

Blockchain in the agribusiness sector is just beginning to be applied since the first article was published in 2016. However, it was observed that most publications appear in 2019 and the Scopus platform stands out in terms of the number of publications. It was deduced that research on the subject has grown significantly in the last three years. This upward trend highlights the emerging nature of blockchain and increasing interest from researchers, universities, and organizations, although it was only introduced in 2009 with the Bitcoin core technology. The academic community, after some years, has identified the potential of blockchain and its possible applications.

Sometimes, blockchain is used as a synonym of Bitcoin, having previously been used only for cryptocurrency applications. In terms of the areas of knowledge publishing on blockchain, it was noted that Engineering (25\%), Computer Science (24\%), and Social Science (12\%) were the most evident in Scopus. With WoS, it is the following: Computer Sciences, 32\%; Telecommunications, 17\%; Engineering and Environmental Science, 12\% (Figure 3). However, knowledge areas vary greatly, enriching the subject interdisciplinarity since some studies are classified in more than one knowledge area. Interdisciplinarity is the meeting of different subjects for the construction of new knowledge, either from a pedagogical or epistemological point of view [36]. This breakdown is justified by the fact that blockchain is a technology that needs software developers to create programs and algorithms that adapt to needs. Likewise, the technology is discussed in relation to operation and development, and the application process is still very restricted. The findings suggest that the subject is still in an exploratory phase where the technology development precedes its application. 


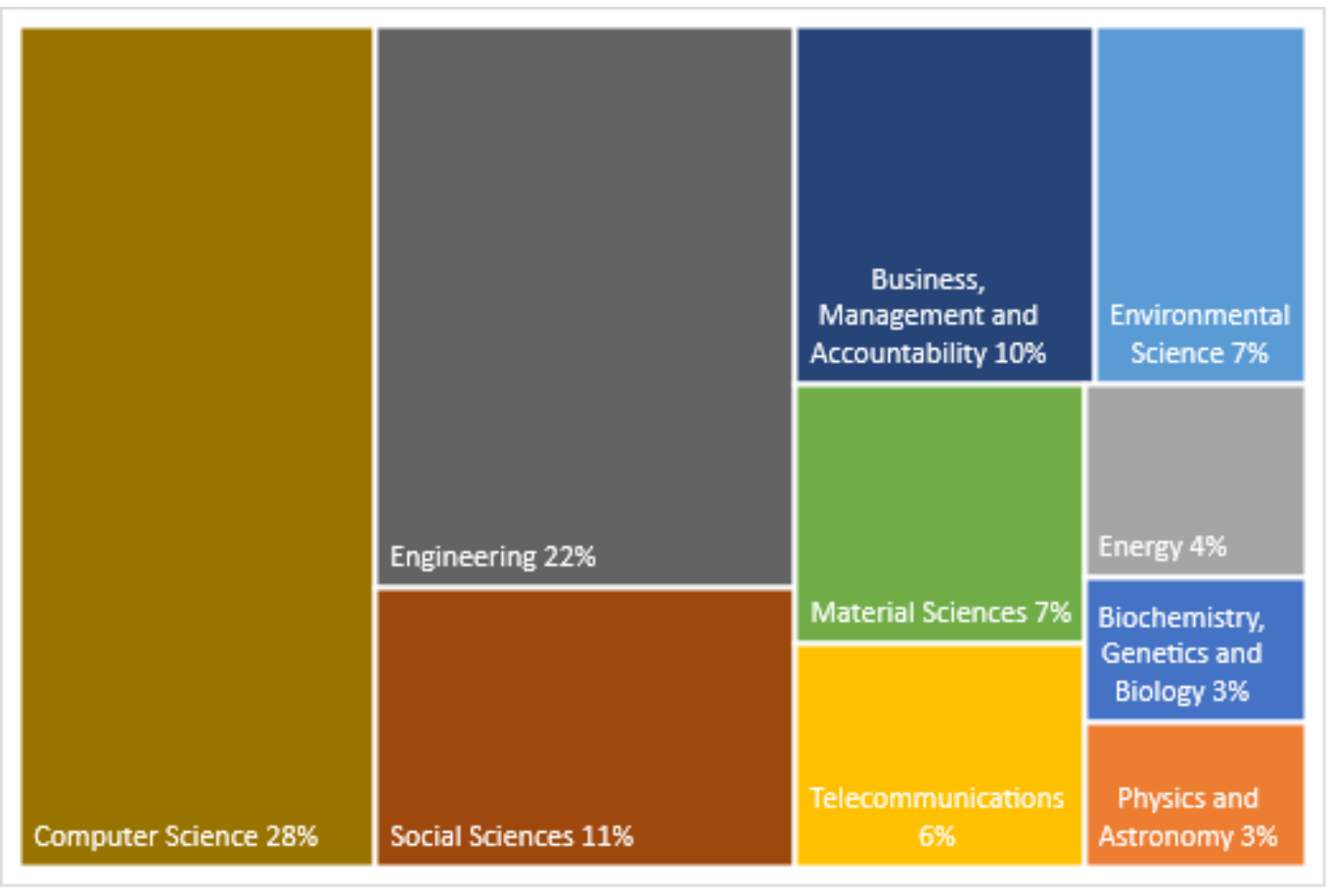

Figure 3. Knowledge areas with the highest number of publications in both databases.

Ten countries stand out, China being the leader in the publishing index, with 39\%, and the USA, with $25 \%$. Together, these two countries account for almost two-thirds of publications worldwide. As for the other countries, Australia, South Africa, Finland, the United Kingdom, Italy, and Germany account for 5\% each, and Spain and Brazil, account for $3 \%$ each. It should be observed that in these countries, there are institutions investing strongly in this technology area, besides being world leaders in technological innovation [37].

The main institutions that stand out in terms of numbers of publications on blockchain in agribusiness are Worcester Polytechnique Institute and Beijing Technology and Business University each with three articles published, and China Agricultural University, National Institute of Industrial Engineering, California State University, Bakersfield, Lancaster University, Shanghai University, Karlsruhe Institute of Technology, Purdue University, and Purdue University System, with two articles each. The first two universities represent the countries that excel in research, located in the USA (Massachusetts) and in China (Pequim), and are known for being prominent in research investment.

The authors that excelled in numbers of publications in Scopus were Hao, Z; Kouhizadeh, M; Mao, D; Wang, F., with three publications, and in WoS, the author Xie, C., with two documents. It should be stressed that only the author Alcarria, R. appeared in both databases, with one publication on each platform, and the others have publications in only one database. Figure 4 shows the last bibliometric indicator of this study, which aimed at generating a word cloud with the most frequent keywords mentioned in the 71 articles.

The word cloud was generated using the 692 keywords extracted from the 71 articles evaluated. It was possible to identify that the most frequent expressions are: Blockchain, Technology, Food, Energy, Smart, Supply Chain, Management, Traceability, System, and Agricultural. It is observed that these words are related to agribusiness, which corroborates the objective of this study. The following is the systematic analysis of the 71 selected studies. 


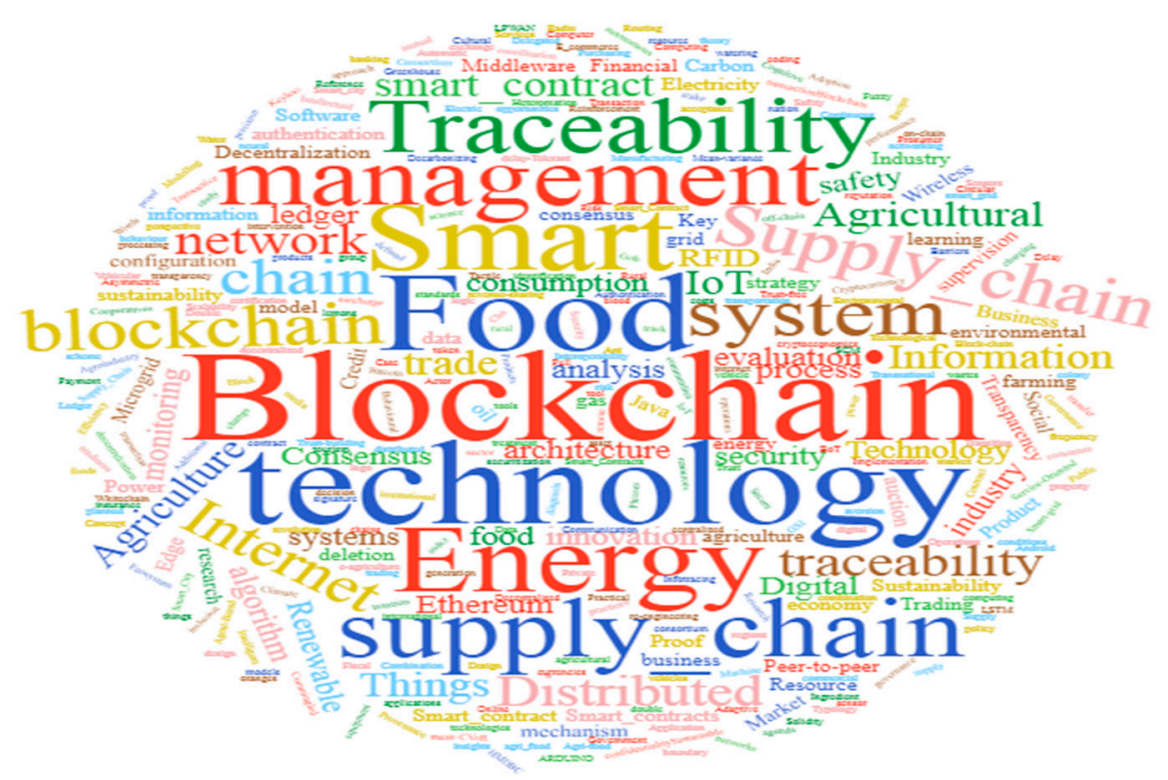

Figure 4. Word cloud of the most frequent keywords in the 71 articles on blockchain in agribusiness.

\subsection{A Qualitative Systematic Review}

Blockchain applications are pointed out in several sectors, including finance, in which a significant percentage of networks were formed and used Blockchain 1.0 for cryptocurrency $[37,38]$. Other authors are categorized according to versions " 2.0 and 3.0 ", which are smart contracts encompassing all the financial and economic areas with efficient applications in economics, markets, general sciences, and governmental areas [34-36]. A scheme of the purposes for which blockchain has been applied in agribusiness was constructed in the analysis of the selected articles, and is outlined in Figure 5. The purposes are related to financial, energy, logistical, environmental, agricultural, cattle breeding and livestock, and industrial management, with some specific uses within each segment. It is important to stress that blockchain implementation has been identified in some supply chains, but they are prototypes still in the laboratory tests and applications phase, which are related and exemplified in the next subsection.

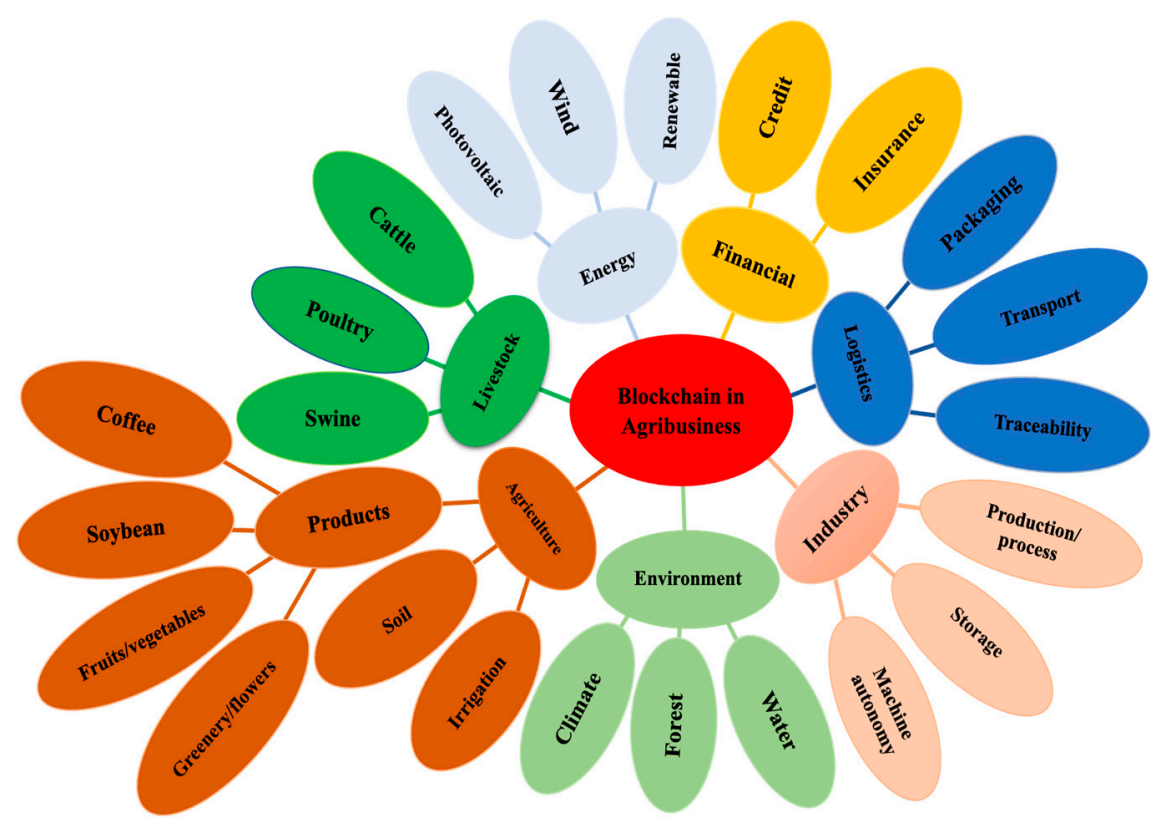

Figure 5. The purposes for which blockchain has been applied in the agribusiness sector. 


\subsubsection{Blockchain Application for Finance in Agribusiness}

Blockchain is considered to be one of the most promising technologies for secure financial transactions for various economic activities, including agribusiness. In agribusiness in particular, it has the potential to revolutionize support for financial transactions for agriculture and improve the credit system. Blockchain allows the reduction of information asymmetry, establishing a fluent channel for transmitting information, increasing the reliability of transactions, improving efficiency, and reducing the costs of agricultural financing $[37,38]$. The mechanisms for recording, storing, validating, and protecting data are aimed at solving financing problems between all actors in agricultural supply chains. This includes farmers, development agencies, banks, insurance companies, and other financial institutions $[37,38]$. The AgriDigital and OlivaCoin platforms, both enabled for blockchain, are cited as examples of faster and safer payment opportunities in rural credit management [7,39]. Tripoli and Schmidhuber [40] state that an integrated payment solution has been launched to increase liquidity in private bonds and global payments using distributed ledger technology (DLT) applied in financing and agricultural insurance through smart contracts.

Hu et al. [41] mention the study applied to delay-tolerant payment that focused on remote rural villages in India, which have a community-run station, such as Nokia Kuha, connected to the public internet through unreliable satellite links. Mao et al. [42] implemented a credit assessment system, adopting blockchain to strengthen the supervision and management of traders in the food supply chain where the entire processing flow and logistics are provided by smart contracts. The smart contracts are programs that combine computer protocols from the user interface to execute the terms of a contract. Since, with blockchain, the whole process becomes more simplified, no longer needing intermediaries involved in asset contracts, it controls the damage of the properties, tangible or intangible, by sharing the access data [43].

\subsubsection{Blockchain Application for Energy in Agribusiness}

The current stage of agricultural development seeks to face the constant increase in production with the use of new equipment and facilities. This makes the agriculture sector a major consumer of energy. In this context, more efficient management of energy resources in agriculture is a fundamental requirement.

Zheng et al. [44] proposed a study to minimize the consumption of photovoltaic energy in greenhouses by using blockchain. In this system, the index that measures the ratio of photovoltaic consumption is defined to assess the condition of consumption in each greenhouse. As a result, the optimal load operation scheme is always recorded on the blockchain. The authors conclude that the blockchain control strategy can effectively improve local energy consumption. This reduces costs with the purchase and losses of energy, improving the quality of electric grid voltage in the farms.

Another application that is also being tested is the development of an irrigation system that minimizes energy consumption, especially in times of drought. In this field of blockchain application, Enescu et al. [45] proposed a study on the use of photovoltaic energy to power a soil improvement system. According to the authors, this technology can help small farmers to better manage water resources during periods of drought.

Blockchain applications for energy purposes have encouraged users to join the renewable energy system. Smart systems are being tested by several industries related to energy production in agriculture. Many of these blockchain applications are still in the pilot project phase, but they already show considerable results in training energy producers and distributors. The technology also acts as a facilitator in the negotiation, bringing greater flexibility, playing an important role in the storage of data, and guaranteeing security in the transactions and commercialization of energy.

Zhang [46] presents a digital coupon or cryptocurrency that could be introduced into the trade of waste, energy and by-products, such as fertilizers or raw materials, among farmers and entrepreneurs. This system could maximize the use of agricultural 
waste by encouraging farmers and companies to work together in the production and commercialization of energy.

\subsubsection{Blockchain Application for Logistics in Agribusiness}

The proper management of logistic processes is essential for every agribusiness supply chain. Blockchain has the potential to facilitate and streamline logistic processes in agribusiness supply chains, and these processes can be reproduced in real time due to complete digitalization and its automation. With the help of smart contracts, financial transfers can be optimized, making them easier [47-49]. For those authors, this generates a guarantee of a direct network between the incoming and outgoing of goods, and payment operations can be carried out with more autonomy and efficiency. The invoices that are currently created on paper and sent by post can become unnecessary with the use of technology.

Blockchain can help lower costs, in addition to adding value to products. The consumer benefits from more transparency and control in the quality of the products. One of the critical points in long supply chains is ensuring food safety. Although the development of traceability mechanisms has brought more security to the consumer, blockchain has elements that can make it a great differentiator in this process. This is one of the most relevant topics in blockchain applications in agribusiness supply chains. Traceability via blockchains allows the consumer to track the food from its origin to retail marketing, where all of the information can be shared securely through a blockchain [50]. According to their preliminary analysis, Lucena et al. [51] concluded that traceability and blockchain-based certification can increase grain exports by $15 \%$ in the Brazilian context. Given that the blockchain allows for the identification of what type of fertilizer was used to grow a given crop, for example, this information can be accessed by retailers, auditors, and governments, among others interested in the supply chain [52].

Another element that facilitates logistical processes in agribusiness supply chains is smart contracts. Choi et al. [53] applied a mean-variance model to evaluate the risk sensitivity of decision-makers, examining the transactions and previous data using blockchain records. They concluded that this technology could facilitate the use of information and increase knowledge about the demand for the products, besides being accompanied by smart contracts, and it can be automated to the contracting mechanism, improving the efficiency of the processes. Chang et al. [54] developed an alternative project of a private chain to increase transparency and collaboration in product process distribution. The project notifies status alterations to concerned parties specified in the smart contract registry; these are captured in real time and information changes are achieved through the push of a button. This technology system proposed in the blockchain achieves a better level of efficiency for logistics and operations. The participants of the supply chain can reduce costs associated with the manual operations for the confirmation of tracking, with installations of expensive information systems such as the Electronic Data Interchange (EDI) and the Enterprise Resource Planning (ERP).

It is worth noting that blockchains can be used in logistics, product identification, and contract design. They allow better visualization of transactions between buyers and sellers, without the intervention of intermediaries. The use of blockchain-based applications in supply chains can guarantee security and induce more consistent contract management among interested parties. Blockchains improve the management performance of complex supply chains and enhance the customer's services and transportation systems with new decentralized architectures.

\subsubsection{Blockchain Application for Environmental Management in Agribusiness}

Agribusiness fights against the image that it negatively impacts the environment [55]. Blockchain can play a key role in the environment due to its data monitoring capability. Research suggests that its adoption can make ecological and sustainable practices in the supply chains easier [56,57]. Lin et al. [24] presented an evaluation tool with social and technical requirements applying blockchains in Information and Communications 
Technology (ICT) systems in agriculture, using an interface to visualize the application in its operation, which can promote better development and incorporation of data into local climate, energy use, pesticides, soil quality, production costs, and biodiversity conservation.

Spreng and Spreng [58] proposed studying advances in Information Technology (IT) using social media, identifying the feasible options for an alternative global transnational climate policy. In the research, they included consumers, fossil fuel industries, non-governmental environmental organizations (NGOs), insurance industries, IT companies, representatives of public administrations, and UN agencies. The label accurately shows the reliability of climate impact and the total energy incorporated into final goods and services. Since the monitoring system is transparent, consumers have more trust in the label.

Paiva Sobrinho et al. [59] present a management proposal for the Jundiaí River Basin, based on the adoption of a complementary currency created with the support of blockchains. Technological innovation, such as payment schemes for environmental systems (PES), does not depend on the traditional financial system. Thus, it is immune to economic crises because its creation and management are independent of banks, with the rewards being paid to the makers in the form of cryptocurrency.

Figorilli et al. [60] implemented a blockchain prototype for open-source electronic wood traceability, using Radio-Frequency Identification (RFID) Technology, in which the process is tracked from the standing tree to the end user. In the first step, the tree is identified in the forest and this first stripe is associated with the information in the database: marking date, Global Positioning System (GPS) point of the tree, species, diameter, and height. Other information such as cutting, labels, stacking and production flows are detected by an antenna where the information is again associated with the database. Therefore, labels are produced during production and sale and applied on the final products destined for the end consumer.

It was identified that the utilization of blockchain in the environment is essentially focused on payments for environmental services, forest mapping, traceability, and climate and soil control. However, it has the potential to be explored in several other ways, including problems of climate change and carbon sequestration.

\subsubsection{Blockchain Application for Agriculture (Farm) in Agribusiness}

Agriculture is one of the most relevant fields in a country, since its production provides food security, nutrition, and health of the population, besides maximizing the economy. In recent years, the agricultural sector has adopted different technologies, such as Internet of Things (IoT) and blockchain, to reach higher yields in production processes [61]. Authors such as Tian [17], Li'na et al. [62], Lin et al. [24], and Mondal et al. [63] have been dedicated to researching the use of blockchain in agriculture, essentially directed to the production traceability.

Li'na et al. [62] proposed an agricultural product based on blockchain and logical architecture in the supply chain, aiming at the involvement and adherence of farmers to technologies to minimize the problem of mutual trust. Those authors presented a food safety traceability system based on blockchain and Electronic Product Code (EPC) Information Services. They developed a prototype to track the product from the farm to the end consumer.

Tao et al. [64] suggested a collaborative tracking system based on blockchain and Electronic Product Code Information Services (EPCIS). The system adopts a smart contract at an innovative business level to solve the issues of disclosing information sensitive to data adulteration and reliability. Kamble et al. [65] analyzed smart contracts and the use of blockchain in fruits and vegetables in India, addressing sustainability issues in human relations between facilitators and Agriculture Supply Chain (ASC) practitioners. The intention was to convince the organizations to adopt blockchain in their supply chains to track production from farms to the final consumer.

Tian [47] and Mondal et al. [63] created blockchain inspired by IoT, that is, an architecture to create a transparent food supply chain. For this purpose, they used blockchain, IoT, 
and RFID indexing terms. According to the authors, the sensing modality was integrated with the identification for tracking and monitoring the quality of the packages, with the food being digitized at different times along the way and the sensor data being updated, in real time, using blockchain, providing a counterfeit-proof digital history. Therefore, any consumer can check, in public accounting, the information on the food packages.

Dos Santos et al. [66] proposed a prototype for the certification and traceability of food products, aiming at tracing the origins of the raw materials without revealing confidential business information. They used the code within Rinkeby Testnet blockchain, applying it to practical examples, including peanuts, cocoa, and apple juice, which are basic ingredients of recipes, thus, demonstrating the feasibility of using the Ingredient Token (IGR) as a methodological figure of certification of ingredients from the farmer to the final consumer, without exposing the formula of the product mixture.

Patil et al. [67] presented a proposal for agriculture with a smart greenhouse, based on activities managed by blockchains, which works through IoT devices. In the project, the authors exhibited this model to achieve security, a light and decentralized privacy project, optimization of resources, and energy consumption. Munir et al. [68] outlined a project, based on an IoT system, used to monitor gardens, controllable from anywhere using a smartphone. The system uses input data collected in real time by sensors that guide farmers and gardeners with a mobile device displaying a list of suggested plants, according to the climate of a particular region.

Scuderi et al. [69] demonstrated the application of blockchain to citrus fruit production in Italy, specifically that referring to Near Field Communication (NFC), in which the process phases involving orange juice are: production, processing, distribution, and sales, with records in a digital profile. According to the authors, key information about citrus farms is stored in digital profiles including the environment and cultivation, soil, water, area, season, plant quality, growing conditions, planting season, and information on the fertilizers and pesticides used for growing oranges. Then, the product is marketed after a digital contract is signed and stored in blockchain.

Borrero [70] tested a traceability system for the food supply chain using blockchain, helping the agricultural cooperatives improve transparency on the origin and processes incorporated into the products. They developed a proof-of-concept blockchain model (PoC) in the agri-food field for the traceability of the supply chain, proving the origin of berry production, and personalizing the roles of each actor in the supply chain. Blockchain, developed with this PoC concept, is being implemented and tested in a Spanish Agricultural Cooperative that uses a book with permissions (hyperledger), based on a smart contract. The demonstration was based on a previous analysis of the berry chain and the interactions between farmers, cooperatives, their certifiers, suppliers, and supermarkets to allow the digital representation of a large number of berries to be associated with a single digital certification.

Salah et al. [71] suggested a system of sequence diagrams based on blockchain for soybean traceability. They also created an algorithm model for selling soy among the several participants, using smart contracts to track and control all interactions and transactions of the participants involved in the ecosystem of the supply chain.

It is inferred that blockchain is being used in the agricultural sector to improve food security, the production process, processing, and transport, besides being applied in a management system of the supply chain to provide transparency, safety, neutrality, and reliability in all the operations of the supply chains. Blockchain, together with IoT, contributes to the resolution of challenges related to operation safety, quality certification, and product origin.

\subsubsection{Blockchain Application for Livestock in Agribusiness}

The livestock sector is in constant evolution, requiring effective alternatives for its process and management. Advances in transportation and communication technologies promote the development of world markets and facilitate the establishment of animal pro- 
duction units. In that context, several authors have been discussing the use and possibility of blockchain in that sector.

Liu et al. [72] highlight the application of blockchain in the pig meat supply chain by addressing its influence on information sharing and state that it solves problems of matching supply and demand in the supply chain. They added that the transaction costs between the actors involved can be reduced, bringing several benefits: time, money, and improvement for the whole chain through efficient management of the farms.

Sittón-Candanedo et al. [73] implemented a blockchain platform on a dairy farm to minimize costs, through which it was possible to identify and use the available resources more efficiently, besides making it possible to track the animals' locations and monitor their health conditions in real time.

Sander et al. [74] designed a study on the acceptance of blockchain in the traceability and transparency of the meat supply chain. They highlighted the different perspectives and opinions of stakeholders, investigating the transparency and traceability system (TTS) of certification and customers' perceptions as to the potential of technology in traceability. The results of adopting the technology as a solution for the current problems affecting the meat production chain in several countries, including Brazil, are promising.

\subsubsection{Blockchain Application for Agroindustry}

Blockchain can be used in the food industry in different ways since production goes through processing and final packaging to the consumer. Several pieces of research have been carried out focusing on this sector using, for example, two-dimensional bar code ( $Q R$ Code) technology, which can already be used in many product packages, since it makes it possible to save a variety of data in a minimal amount of space. The final consumer can view the whole history of the product, from production, processing, to final packaging, on a smartphone [64,65].

The first applications are already being tested in retail companies. Walmart, in partnership with IBM, is using the technology in the traceability of mangoes and pig meat, since it is possible to track the entire supply chain in a few seconds. Furthermore, with blockchain, there is the possibility of identifying contaminated products and eliminating them quickly and efficiently [75]. Blockchain has been also tested for traceability in the milk industry. Behnke and Janssen [76] researched four different dairy industries with distinct features. They investigated every process in the supply chain, from mass production to small product batches, and identified the conditions of information ensuring improvements in batch traceability.

Kouhizadeh et al. [56] propose the application of blockchain in a research context in the circular economy. The authors identified the various ways in which those areas interact between management research and its implications, improving the country's economy and the environment. They conducted the study with initiatives of circular economy at three levels: macro, meso, and micro. Thus, they identified how technology can contribute to the product, its suppression, and its synergies.

Zhu and Kouhizadeh [11] conducted a case study with industries to track the sales performance of their products using blockchain. The uses of blockchain aimed at supplying the following sustainability efforts in the chain: management, product reuse (recycling), regeneration, manufacture, and waste management, which can be tracked for decision making and product disposal. The blockchain can track information from stakeholders such as retailers and customers.

Tallyn et al. [77] developed a Bitbarista prototype with the objective of providing opportunities for the creation of autonomous systems aiming at contributing to the most independent and transparent organizations. The research presented a study conducted in three environments in an office, for one month, exploring the impact of an autonomous coffee machine in the daily activity of coffee consumption. The Bitbarista measures the coffee consumption using autonomous processes in blockchain, presenting the data of origin at the time of the purchase, while aiming to reduce intermediaries in the trade of 
this product. The report of interactions with the Bitbarista and around it explores the implications for daily life, its structures, and social values.

It has been identified that the technology can be successfully implemented in various sectors and departments of an industry, which allows understanding for how to apply blockchain in the development of daily activities within an industry.

\section{Conclusions}

Based on the bibliometric analyses, as in the results presented, it was found that the blockchain subject has grown in academia in recent years. However, regarding the analysis of the studies, it was possible to ascertain that, although blockchain emerged more than ten years ago, the discussion of its application in the context of agribusiness is still very recent. Moreover, as the technology development moves first in science, it is possible to say that practical applications in agribusiness supply chains are less advanced.

It was verified that most publications are concentrated in the areas of Computer Science and Engineering, which is justified by the fact that blockchain is a technology that requires software developers to create models adapted to certain demands. Blockchain development is concentrated in countries such as the United States and China. Although American agribusiness is well developed, other countries where the sector plays an important role, such as Brazil, have made a modest contribution to the scientific development of blockchain technology.

It is relevant to note that research on the application of blockchains in agribusiness segments is still at an early stage, including its experimentation. In the case of this study, laboratory prototypes were found in the analysis of the articles, which are in the application testing phase. There are several applications of the technology in the "proof of concept" phase, and few are implemented on a large scale. There are other application possibilities, since its potential at the moment may not be correctly estimated, as it is still an emerging technology.

Financial, energy, logistical, environmental, agricultural, livestock, and industrial are the main purposes for which blockchain has been applied in agribusiness supply chains, as reported in the scientific literature. The purposes are not independent or mutually exclusive of each other. On the contrary, blockchain application in agribusiness supply chains can provide cross-factor benefits. Blockchain applications with a logistical purpose, for instance, may also result in energy, financial, and environmental advantages.

Blockchain is a technology in development within different sectors, with several application possibilities and vast advantages, such as an increase in confidence, reduction of risks in transactions, less bureaucracy, reduction of costs due to the elimination of intermediaries, reduction of risks and frauds, and greater privacy due to the rigorous controls made much more secure due to the immutability of the data. Evidence has been identified that blockchain brings countless benefits when used in agribusiness supply chains by reducing intermediaries and transactional cost, and improving the processes as a whole. It enables the transformation of different transactional processes, making them simpler and faster. Accordingly, the use of blockchain in agribusiness supply chains can facilitate collaboration safely and reliably among the participants involved in business networks. Traceability and smart contracts are frequently reported as advantageous applications in agribusiness.

For future studies, it is suggested that issues, such as transaction costs, information governance, new business models, information asymmetry, and the use of blockchain as a management tool in the agribusiness sectors, be explored. Another area for investigation is the implementation cost of that technology.

Author Contributions: Conceptualization, G.d.S.R.R. and L.d.O.; methodology, G.d.S.R.R. and L.d.O.; software, G.d.S.R.R. and L.d.O.; validation, G.d.S.R.R., L.d.O., and E.T.; formal analysis, G.d.S.R.R., L.d.O., and E.T.; investigation, G.d.S.R.R. and L.d.O.; resources, G.d.S.R.R., L.d.O., and E.T.; data curation, G.d.S.R.R. and L.d.O.; writing—original draft preparation, G.d.S.R.R. and L.d.O.; writing - review and editing, G.d.S.R.R., L.d.O., and E.T.; visualization, G.d.S.R.R. and L.d.O.; supervision, L.d.O.; project administration, G.d.S.R.R. and L.d.O.; funding acquisition, G.d.S.R.R. and E.T. All authors have read and agreed to the published version of the manuscript. 
Funding: This study was partially funded by the Coordenação de Aperfeiçoamento de Pessoal de Nivel Superior-Brasil (CAPES) through a scholarship granted for the first author (Process Number 88882.439355/2019-01), and by the National Council for Scientific and Technological DevelopmentCNPq through a research grant (Process Number 303956/2019-4).

Institutional Review Board Statement: Not applicable.

Informed Consent Statement: Not applicable.

Data Availability Statement: Not applicable.

Acknowledgments: The author are grateful to the Graduate Program in Agribusiness at the Universidade Federal do Rio Grande do Sul-UFRGS, the Coordenação de Aperfeiçoamento de Pessoal de Nível Superior-Brasil (CAPES), and the National Council for Scientific and Technological Development (CNPq). The authors thank the anonymous reviewers for their comments and suggestions.

Conflicts of Interest: The authors declare no conflict of interest.

\section{References}

1. Jank, M.S.; Nassar, A.M.; Tachinardi, M.H. Agronegócio e comércio exterior brasileiro. Rev. USP 2005, 14. [CrossRef]

2. Furlanetto, E.L.; Cândido, G.A. Metodologia para estruturação de cadeias de suprimentos no agronegócio: Um estudo exploratório. Rev. Bras. Eng. Agrícola Ambient. 2006, 10, 772-777. [CrossRef]

3. Durski, G.R. Avaliação do desempenho em cadeias de suprimentos. Rev. FAE 2003, 6, 27-38.

4. Pedroso, M.C.; Nakano, D. Knowledge and information flows in supply chains: A study on pharmaceutical companies. Int. J. Prod. Econ. 2009, 122, 376-384. [CrossRef]

5. Kaipia, R. Coordinating material and information flows with supply chain planning. Int. J. Logist. Manag. 2009, $20,144-162$. [CrossRef]

6. Kembro, J.; Näslund, D.; Olhager, J. Information sharing across multiple supply chain tiers: A Delphi study on antecedents. Int. J. Prod. Econ. 2017, 193, 77-86. [CrossRef]

7. Kamilaris, A.; Fonts, A.; Prenafeta-Boldv́, F.X. The rise of blockchain technology in agriculture and food supply chains. Trends Food Sci. Technol. 2019, 91, 640-652. [CrossRef]

8. Flores, L.; Sanchez, Y.; Ramos, E.; Sotelo, F.; Hamoud, N. Blockchain in Agribusiness Supply Chain Management: A Traceability Perspective. In Advances in Artificial Intelligence, Software and Systems Engineering; Ahram, T., Ed.; Springer: Berlin/Heidelberg, Germany, 2021; pp. 465-472.

9. Rejeb, A.; Keogh, J.G.; Treiblmaier, H. Leveraging the Internet of Things and Blockchain Technology in Supply Chain Management. Future Internet 2019, 11, 161. [CrossRef]

10. Leng, K.; Bi, Y.; Jing, L.; Fu, H.-C.; Van Nieuwenhuyse, I. Research on agricultural supply chain system with double chain architecture based on blockchain technology. Future Gener. Comput. Syst. 2018, 86, 641-649. [CrossRef]

11. Zhu, Q.; Kouhizadeh, M. Blockchain Technology, Supply Chain Information, and Strategic Product Deletion Management. IEEE Eng. Manag. Rev. 2019, 47, 36-44. [CrossRef]

12. Christidis, K.; Devetsikiotis, M. Blockchains and Smart Contracts for the Internet of Things. IEEE Access 2016, 4, 2292-2303. [CrossRef]

13. Laurence, T. Blockchain for Dummies; John Wiley \& Sons, Inc.: Hoboken, NJ, USA, 2017.

14. Sikorski, J.J.; Haughton, J.; Kraft, M. Blockchain technology in the chemical industry: Machine-to-machine electricity market. Appl. Energy 2017, 195, 234-246. [CrossRef]

15. Fernández Herrero, D. Aplicación de la Tecnología Blockchain en el Supply Chain en los Sectores Industriales, Escuela de Ingenierías Industriales. Master's Thesis, Univesidad de Valladolid, Valladolid, Spain, 2018.

16. Yang, R.; Wakefield, R.; Lyu, S.; Jayasuriya, S.; Han, F.; Yi, X.; Yang, X.; Amarasinghe, G.; Chen, S. Public and private blockchain in construction business process and information integration. Autom. Constr. 2020, 118, 103276. [CrossRef]

17. Tian, F. An information System for Food Safety Monitoring in Supply Chains Based on HACCP, Blockchain and Internet of Things. Ph.D. Thesis, WU Vienna University of Economics and Business, Vienna, Austria, 2018.

18. Atzori, M. Blockchain technology and decentralized governance: Is the state still necessary? J. Gov. Regul. 2017, 6, 45-62. [CrossRef]

19. Casino, F.; Dasaklis, T.K.; Patsakis, C. A systematic literature review of blockchain-based applications: Current status, classification and open issues. Telemat. Inform. 2019, 36, 55-81. [CrossRef]

20. Ferreira, J.E.; Pinto, F.G.C.; dos Santos, S.C. Estudo de Mapeamento Sistemático sobre as Tendências e Desafios do Blockchain. Rev. Gestão Org. 2017, 15, 108-117. [CrossRef]

21. Lezoche, M.; Hernandez, J.E.; Díaz, M.M.E.A.; Panetto, H.; Kacprzyk, J. Agri-food 4.0: A survey of the supply chains and technologies for the future agriculture. Comput. Ind. 2020, 117, 103187. [CrossRef]

22. Xie, C.; Sun, Y.; Luo, H. Secured Data Storage Scheme Based on Block Chain for Agricultural Products Tracking. In Proceedings of the 2017 3rd International Conference on Big Data Computing and Communications (BIGCOM), Chengdu, China, 10-11 August 2017; IEEE: Piscataway, NJ, USA, 2017; pp. 45-50. 
23. Papa, S.F. Use of Blockchain Technology in Agribusiness: Transparency and Monitoring in Agricultural Trade. In Proceedings of the 2017 International Conference on Management Science and Management Innovation (MSMI 2017), Suzhou, China, 23-25 June 2017; Atlantis Press: Paris, France, 2017.

24. Lin, Y.-P.; Petway, J.; Anthony, J.; Mukhtar, H.; Liao, S.-W.; Chou, C.-F.; Ho, Y.-F. Blockchain: The Evolutionary Next Step for ICT E-Agriculture. Environments 2017, 4, 50. [CrossRef]

25. Tse, D.; Zhang, B.; Yang, Y.; Cheng, C.; Mu, H. Blockchain application in food supply information security. In Proceedings of the 2017 IEEE International Conference on Industrial Engineering and Engineering Management (IEEM), Singapore, 10-13 December 2017; IEEE: Piscataway, NJ, USA, 2017; pp. 1357-1361.

26. Xiong, H.; Dalhaus, T.; Wang, P.; Huang, J. Blockchain Technology for Agriculture: Applications and Rationale. Front. Blockchain 2020, 3. [CrossRef]

27. Shew, A.M.; Snell, H.A.; Nayga, R.M.; Lacity, M.C. Consumer valuation of blockchain traceability for beef in the United States. Appl. Econ. Perspect. Policy 2021, aepp.13157. [CrossRef]

28. Garaus, M.; Treiblmaier, H. The influence of blockchain-based food traceability on retailer choice: The mediating role of trust. Food Control 2021, 108082. [CrossRef]

29. Lim, M.K.; Li, Y.; Wang, C.; Tseng, M.-L. A literature review of blockchain technology applications in supply chains: A comprehensive analysis of themes, methodologies and industries. Comput. Ind. Eng. 2021, 154, 107133. [CrossRef]

30. Fu, X.; Wang, H.; Shi, P. A survey of Blockchain consensus algorithms: Mechanism, design and applications. Sci. China Inf. Sci. 2021, 64, 121101. [CrossRef]

31. Kononets, Y.; Treiblmaier, H. The potential of bio certification to strengthen the market position of food producers. Mod. Supply Chain Res. Appl. 2020. [CrossRef]

32. Araújo, C.A. Bibliometria: Evolução histórica e questões atuais. Em Questão 2006, 12, 11-32.

33. Moher, D.; Liberati, A.; Tetzlaff, J.; Altman, D.G. Preferred Reporting Items for Systematic Reviews and Meta-Analyses: The PRISMA Statement. PLoS Med. 2009, 6, e1000097. [CrossRef]

34. Cronin, P.; Ryan, F.; Coughlan, M. Undertaking a literature review: A step-by-step approach. Br. J. Nurs. 2008, 17, 38-43. [CrossRef]

35. Tranfield, D.; Denyer, D.; Smart, P. Towards a Methodology for Developing Evidence-Informed Management Knowledge by Means of Systematic Review. Br. J. Manag. 2003, 14, 207-222. [CrossRef]

36. Bispo, E.P.d.F.; Tavares, C.H.F.; Tomaz, J.M.T. Interdisciplinaridade no ensino em saúde: O olhar do preceptor na Saúde da Família. Interface Commun. Saúde Educ. 2014, 18, 337-350. [CrossRef]

37. Tapscott, D.; Tapscott, A. How Blockchain Will Change Organizations. MIT Sloan Manag. Rev. 2017, 58, $10-13$.

38. Swan, M. Blockchain-Blueprint for a New Economy; O'Reilly Media, Inc.: Sebastopol, CA, USA, 2015.

39. Haferkorn, M.; Quintana Diaz, J.M. Seasonality and Interconnectivity Within Cryptocurrencies-An Analysis on the Basis of Bitcoin, Litecoin and Namecoin. In Enterprise Applications and Services in the Finance Industry; Lugmayr, A., Ed.; Springer: Berlin/Heidelberg, Germany, 2015; pp. 106-120.

40. Tripoli, M.; Schmidhuber, J. Emerging Opportunities for the Application of Blockchain in the Agri-Food Industry; FAO: Rome, Italy, 2018; 40p.

41. Hu, Y.; Manzoor, A.; Ekparinya, P.; Liyanage, M.; Thilakarathna, K.; Jourjon, G.; Seneviratne, A. A Delay-Tolerant Payment Scheme Based on the Ethereum Blockchain. IEEE Access 2019, 7, 33159-33172. [CrossRef]

42. Mao, D.; Wang, F.; Hao, Z.; Li, H. Credit Evaluation System Based on Blockchain for Multiple Stakeholders in the Food Supply Chain. Int. J. Environ. Res. Public Health 2018, 15, 1627. [CrossRef] [PubMed]

43. Nofer, M.; Gomber, P.; Hinz, O.; Schiereck, D. Blockchain. Bus. Inf. Syst. Eng. 2017, 59, 183-187. [CrossRef]

44. Zheng, C.; Jianhua, Y.; Kaiyuan, J.; Bin, H.; Weizhou, W. Control strategy of time-shift facility agriculture load and photovoltaic local consumption based on energy blockchain. Electr. Power Autom. Equip. 2021, 41, 47-55. [CrossRef]

45. Enescu, F.M.; Bizon, N.; Stirbu, C. Smart Energy Grids used in irrigation systems using the blockchain applications. In Proceedings of the 2019 11th International Conference on Electronics, Computers and Artificial Intelligence (ECAI), Pitesti, Romania, 27-29 June 2019; IEEE: Piscataway, NJ, USA, 2019; pp. 1-6.

46. Zhang, D. Application of Blockchain Technology in Incentivizing Efficient Use of Rural Wastes: A case study on Yitong System. Energy Procedia 2019, 158, 6707-6714. [CrossRef]

47. Tian, F. An agri-food supply chain traceability system for China based on RFID \& blockchain technology. In Proceedings of the 2016 13th International Conference on Service Systems and Service Management (ICSSSM), Kunming, China, 24-26 June 2016; IEEE: Piscataway, NJ, USA, 2016; pp. 1-6.

48. Raskin, M. The law and legality of Smart Contracts. Georg. Law Technol. Rev. 2017, 1, 305-341.

49. Mao, D.; Hao, Z.; Wang, F.; Li, H. Novel Automatic Food Trading System Using Consortium Blockchain. Arab. J. Sci. Eng. 2019, 44, 3439-3455. [CrossRef]

50. Bechtsis, D.; Tsolakis, N.; Bizakis, A.; Vlachos, D. A Blockchain Framework for Containerized Food Supply Chains. Comput. Aided Chem. Eng. 2019, 46, 1369-1374. [CrossRef]

51. Lucena, P.; Binotto, A.P.D.; da Silva Momo, F.; Kim, H. A Case Study for Grain Quality Assurance Tracking based on a Blockchain Business Network. arXiv 2018, arXiv:1803.07877. 
52. Janssen, S.J.C.; Porter, C.H.; Moore, A.D.; Athanasiadis, I.N.; Foster, I.; Jones, J.W.; Antle, J.M. Towards a new generation of agricultural system data, models and knowledge products: Information and communication technology. Agric. Syst. 2017, 155, 200-212. [CrossRef]

53. Choi, T.-M.; Wen, X.; Sun, X.; Chung, S.-H. The mean-variance approach for global supply chain risk analysis with air logistics in the blockchain technology era. Transp. Res. Part E Logist. Transp. Rev. 2019, 127, 178-191. [CrossRef]

54. Chang, S.E.; Chen, Y.-C.; Lu, M.-F. Supply chain re-engineering using blockchain technology: A case of smart contract based tracking process. Technol. Forecast. Soc. Chang. 2019, 144, 1-11. [CrossRef]

55. Rajão, R.; Soares-Filho, B.; Nunes, F.; Börner, J.; Machado, L.; Assis, D.; Oliveira, A.; Pinto, L.; Ribeiro, V.; Rausch, L.; et al. The rotten apples of Brazil's agribusiness. Science 2020, 369, 246-248. [CrossRef]

56. Kouhizadeh, M.; Sarkis, J.; Zhu, Q. At the Nexus of Blockchain Technology, the Circular Economy, and Product Deletion. Appl. Sci. 2019, 9, 1712. [CrossRef]

57. Saberi, S.; Kouhizadeh, M.; Sarkis, J.; Shen, L. Blockchain technology and its relationships to sustainable supply chain management. Int. J. Prod. Res. 2019, 57, 2117-2135. [CrossRef]

58. Spreng, C.P.; Spreng, D. Paris is not enough: Toward an Information Technology (IT) enabled transnational climate policy. Energy Res. Soc. Sci. 2019, 50, 66-72. [CrossRef]

59. Paiva Sobrinho, R.; Garcia, J.R.; Maia, A.G.; Romeiro, A.R. Tecnologia Blockchain: Inovação em Pagamentos por Serviços Ambientais. Estud. Avançados 2019, 33, 151-176. [CrossRef]

60. Figorilli, S.; Antonucci, F.; Costa, C.; Pallottino, F.; Raso, L.; Castiglione, M.; Pinci, E.; Del Vecchio, D.; Colle, G.; Proto, A.; et al. A Blockchain Implementation Prototype for the Electronic Open Source Traceability of Wood along the Whole Supply Chain. Sensors 2018, 18, 3133. [CrossRef] [PubMed]

61. Pivoto, D.; Waquil, P.D.; Talamini, E.; Finocchio, C.P.S.; Dalla Corte, V.F.; de Vargas Mores, G. Scientific development of smart farming technologies and their application in Brazil. Inf. Process. Agric. 2018, 5, 21-32. [CrossRef]

62. Li'na, Y.; Guofeng, Z.; Jingdun, J.; Wanlin, G.; Ganghong, Z.; Sha, T. Modern Agricultural Product Supply Chain Based on Block Chain Technology. Trans. Chin. Soc. Agric. Mach. 2017, 48, 387-393. [CrossRef]

63. Mondal, S.; Wijewardena, K.P.; Karuppuswami, S.; Kriti, N.; Kumar, D.; Chahal, P. Blockchain Inspired RFID-Based Information Architecture for Food Supply Chain. IEEE Internet Things J. 2019, 6, 5803-5813. [CrossRef]

64. Tao, Q.; Cui, X.; Huang, X.; Leigh, A.M.; Gu, H. Food Safety Supervision System Based on Hierarchical Multi-Domain Blockchain Network. IEEE Access 2019, 7, 51817-51826. [CrossRef]

65. Kamble, S.S.; Gunasekaran, A.; Sharma, R. Modeling the blockchain enabled traceability in agriculture supply chain. Int. J. Inf. Manag. 2020, 52, 101967. [CrossRef]

66. Dos Santos, R.; Torrisi, N.; Yamada, E.; Pantoni, R. IGR Token-Raw Material and Ingredient Certification of Recipe Based Foods Using Smart Contracts. Informatics 2019, 6, 11. [CrossRef]

67. Patil, A.S.; Tama, B.A.; Park, Y.; Rhee, K.-H. A Framework for Blockchain Based Secure Smart Green House Farming. In Advances in Computer Science and Ubiquitous Computing; Park, J., Loia, V., Yi, G., Sung, Y., Eds.; Springer: Berlin/Heidelberg, Germany, 2018; pp. 1162-1167.

68. Munir, M.S.; Bajwa, I.S.; Cheema, S.M. An intelligent and secure smart watering system using fuzzy logic and blockchain. Comput. Electr. Eng. 2019, 77, 109-119. [CrossRef]

69. Scuderi, A.; Foti, V.; Timpanaro, G. The supply chain value of POD and PGI food products through the application of blockchain. Qual. Success 2019, 20, 580-587.

70. Borrero, J.D. Sistema de trazabilidad de la cadena de suministro agroalimentario para cooperativas de frutas y hortalizas basado en la tecnología Blockchain. CIRIEC-España Rev. Econ. Pública Soc. Coop. 2019, 71. [CrossRef]

71. Salah, K.; Nizamuddin, N.; Jayaraman, R.; Omar, M. Blockchain-Based Soybean Traceability in Agricultural Supply Chain. IEEE Access 2019, 7, 73295-73305. [CrossRef]

72. Liu, L.; Li, F.; Qi, E. Research on Risk Avoidance and Coordination of Supply Chain Subject Based on Blockchain Technology. Sustainability 2019, 11, 2182. [CrossRef]

73. Sittón-Candanedo, I.; Alonso, R.S.; Corchado, J.M.; Rodríguez-González, S.; Casado-Vara, R. A review of edge computing reference architectures and a new global edge proposal. Future Gener. Comput. Syst. 2019, 99, 278-294. [CrossRef]

74. Sander, F.; Semeijn, J.; Mahr, D. The acceptance of blockchain technology in meat traceability and transparency. Br. Food J. 2018, 120, 2066-2079. [CrossRef]

75. Yiannas, F. A New Era of Food Transparency Powered by Blockchain. Innov. Technol. Gov. Glob. 2018, 12, 46-56. [CrossRef]

76. Behnke, K.; Janssen, M.F.W.H.A. Boundary conditions for traceability in food supply chains using blockchain technology. Int. J. Inf. Manag. 2020, 52, 101969. [CrossRef]

77. Tallyn, E.; Pschetz, L.; Gianni, R.; Speed, C.; Elsden, C. Exploring Machine Autonomy and Provenance Data in Coffee Consumption. Proc. ACM Hum.-Comput. Interact. 2018, 2, 1-25. [CrossRef] 